\title{
Elevating dairy research and extension through partnership: Outcomes from the United States Department of Agriculture and National Dairy Council collaborative meeting to develop a coordination roadmap*
}

\author{
J. M. Tricarico, ${ }^{1} \dagger$ M. L. Slimko, ${ }^{2}$ W. B. Graves, ${ }^{2}$ M. D. Eve, ${ }^{3}$ and J. A. Thurston ${ }^{4}$ \\ ${ }^{1}$ Innovation Center for US Dairy, Rosemont, IL 60018 \\ ${ }^{2}$ National Dairy Council, Rosemont, IL 60018 \\ ${ }^{3}$ USDA, Agricultural Research Service, Beltsville, MD 20705 \\ ${ }^{4}$ USDA, National Institute of Food and Agriculture, Washington, DC 20024
}

\section{ABSTRACT}

Dairy foods provide a significant portion of the recommended daily nutrition for much of the US population. Improving the availability of safe and nutritious dairy products and decreasing the environmental impact of the dairy community continue to be high priorities for both industry and the public sector. In recognition of these shared priorities, scientists and other specialists from the USDA, National Dairy Council, industry, academia, and nongovernmental organizations participated in the "Elevating Dairy Research and Extension Through Partnership" meeting on June 19, 2018. The purpose of the meeting was to strengthen partnerships and identify dairy-related research and extension needs in human nutrition, environmental sustainability, food safety, and product innovation that would benefit from enhanced coordination and collaboration across the dairy community, academia, and government. To catalyze further progress on these topics, the meeting organizers agreed to leverage the content and expertise that emerged from the meeting to develop a dairy research and extension coordination roadmap. The roadmap will establish and articulate a vision for coordinated collaboration between USDA researchers, the National Dairy Council, university researchers, extension specialists, and other dairy community stakeholders in the private and public sectors. This article represents the proceedings of the meeting and is intended to broadly communicate the dairy research and extension discussion and next steps to the dairy research and extension communities and other stakeholders in industry, academic, and government sectors.

Received March 6, 2019

Accepted May 28, 2019.

*National Dairy Council is managed by Dairy Management Inc., Rosemont, IL.

†Corresponding author: Juan.Tricarico@dairy.org
Key words: dairy, agriculture, research, public-private partnership, extension

\section{INTRODUCTION}

The demand for animal-derived foods, including milk and dairy products, is estimated to double in response to increases in population, urbanization, and income across the world (Gerber and Steinfeld, 2008). Dairy foods are at the intersection of social, environmental, and economic components of sustainable, nutritious diets. When assessed by nutrient profile, "milk and milk products" are the only food group that provides both protein and calcium at a relatively low cost of energy, as measured in kilocalories (Drewnowski, 2018). In terms of the environment, dairy production, processing, and consumption contribute approximately $2 \%$ of total US greenhouse gas emissions (Thoma et al., 2013) while utilizing just $5.1 \%$ of US water withdrawal (Henderson et al., 2017). Further, whereas dairy food production requires $8.4 \%$ of US cropland and $3.7 \%$ of US farmland (Henderson et al., 2017), it contributes calcium, vitamin D, potassium, and other essential nutrients to the American diet (Fulgoni et al., 2011). Economically, dairy foods are an affordable choice (Drewnowski, 2018).

In an effort to improve the availability of safe and nutritious dairy foods, understand their role in supporting health, and decrease the environmental impact of their production, distribution, and consumption, representatives from the National Dairy Council (NDC) and the USDA agencies National Institute of Food and Agriculture (NIFA) and Agricultural Research Service (ARS) convened a meeting titled, "Elevating Dairy Research and Extension Through Partnership." This meeting, held on June 19, 2018, at the National Agricultural Library in Beltsville, Maryland, was a concerted effort to think more broadly about the translation and dissemination of dairy-related research by actively engaging 
colleagues in the Land-Grant University Cooperative Extension System to help plan, execute, and communicate research to those who will put it into action (e.g., industry, agriculture, academia, government, and the public). Additional attendees included representatives from the USDA-Economic Research Service, researchers from various land-grant universities and academia, the Foundation for Food and Agriculture Research, United States Dairy Export Council, the National Milk Producers Federation, industry, Innovation Center for US Dairy, and other nonprofit organizations. The overall purpose of the meeting was to strengthen partnerships and engage in discussion topics for research and extension in nutrition, environmental sustainability, and food safety and products through the development of a dairy research and extension coordination roadmap. The objective of the roadmap is to establish and articulate a vision for coordinated collaboration between dairy community stakeholders in the private and public sectors.

\section{PUBLIC-PRIVATE PARTNERSHIP}

Research collaboration between the USDA and NDC was formally established in 2007, when the National Dairy Research Program (NDRP) was launched. The NDRP was a collaborative research effort meant to develop the scientific knowledge that would help enhance the domestic and global markets for US dairy producers and manufacturers; remove barriers to dairy consumption and new product development; improve the nation's nutrition and health; and assist in providing for a strong national defense. Since then, several memorandums of understanding between USDA and NDC have affirmed the commitment to mutual areas of interest between the public-private partners. A collaborative research-planning meeting held in 2016 (Slimko et al., 2017) resulted in several research collaborations that have since helped foster co-funding, joint programming, stakeholder input, co-authorship, and requests to serve on peer-review panels (Table 1). These collaborations continue to benefit USDA, NDC, and the dairy research community overall by catalyzing discussion and action focused on addressing critical research needs. Ultimately, these collaborations positively affect the agricultural sector that USDA and NDC serve.

\section{CONTEXT FOR A DAIRY RESEARCH AND EXTENSION COORDINATION ROADMAP}

The need for coordinated research and extension efforts to supply sustainably produced, safe, and nutritious dairy foods and ingredients exists within a complex context that includes several challenges. The world population is expected to increase to almost 10 billion by 2050 , with an associated increase in urbanization and growth of the middle class that may double the demand for animal-derived foods, including milk and dairy foods (Perdue, 2017). Public spending on agricultural research and development is in decline in the United States to the extent that it has been surpassed by China (Clancy et al., 2016). The growing disconnect between the food industry and agricultural production on one side and human nutrition and public health on the other, adds confusion to already complex topics that affect food production, animals, people, and the environment (N. Fukagawa, USDA, ARS, Beltsville, MD; personal communication). Quantifying unintended consequences and trade-offs associated with food system changes is essential to sustaining healthy people in a healthy environment (White and Hall, 2017). Transdisciplinary research on human nutrition, food safety, product development, and environmental stewardship requires the management of large complex data sets and integration of research teams across various disciplines and geographical locations (Holly et al., 2018). The pivotal role of extension and outreach on technology transfer and the adoption of innovation raises the question, "if the greatest scientific discovery of all time was not applied to benefit human existence, would it have any value?" (S. Smith, USDA, NIFA, Washington, DC; personal communication). The differences between scientific and consumer jargon referring to environmental sustainability create consumer perceptions of environmental issues as false dichotomies (e.g., grazing versus confined feeding) rather than a spectrum of choice between 2 extremes. This oversimplification of complex issues leads to a variety of unrealistic market and regulatory expectations to be met by private initiatives and global policies. It is within this complex landscape that NDC and USDA attempt to provide leadership through collaboration by convening dairy stakeholders, aligning on key research questions, identifying extension and outreach needs, and establishing a coordinated approach through a dairy research and extension coordination roadmap.

\section{DAIRY RESEARCH AND EXTENSION COORDINATION ROADMAP: A FRAMEWORK}

Collaboration and coordination across federal, industry academic research scientists and Extension professionals is critical for success in addressing today's agricultural challenges and will remain so in the future. Breakout sessions at the "Elevating Dairy Research and Extension Through Partnership" meeting in 2018 in the areas of human nutrition, environmental sustainability, food safety, and product innovation were designed to 
TRICARICO ET AL.
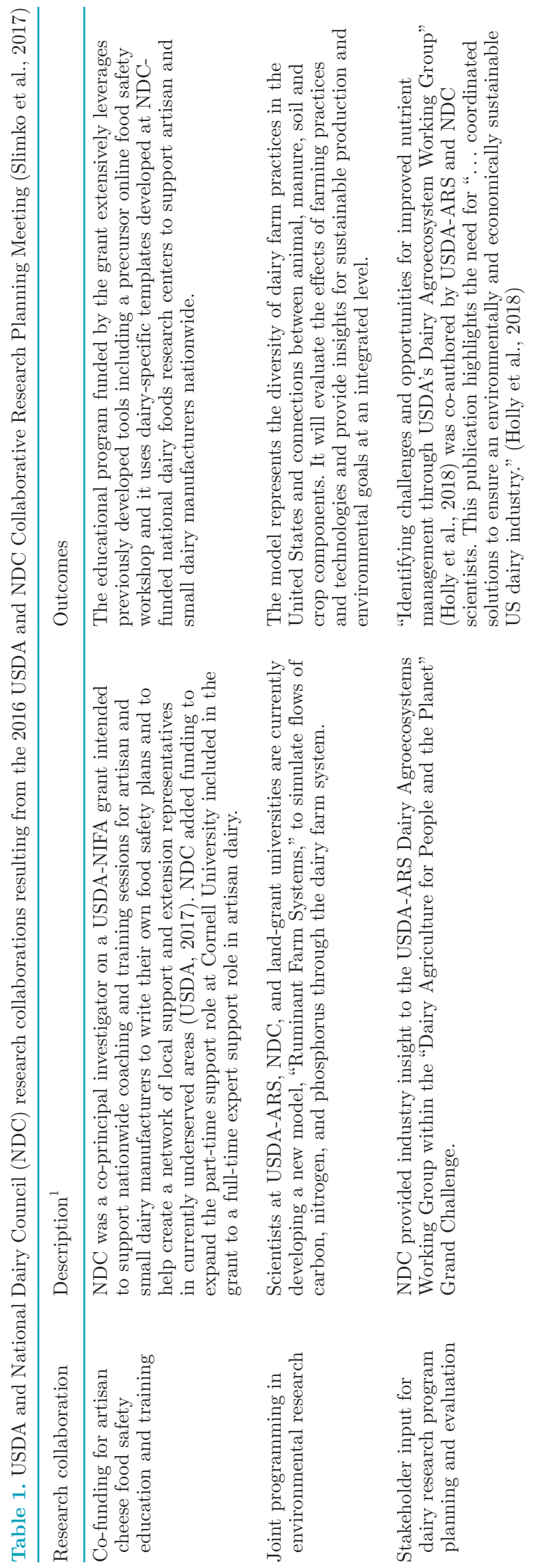

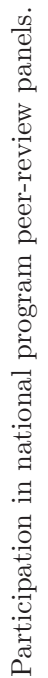

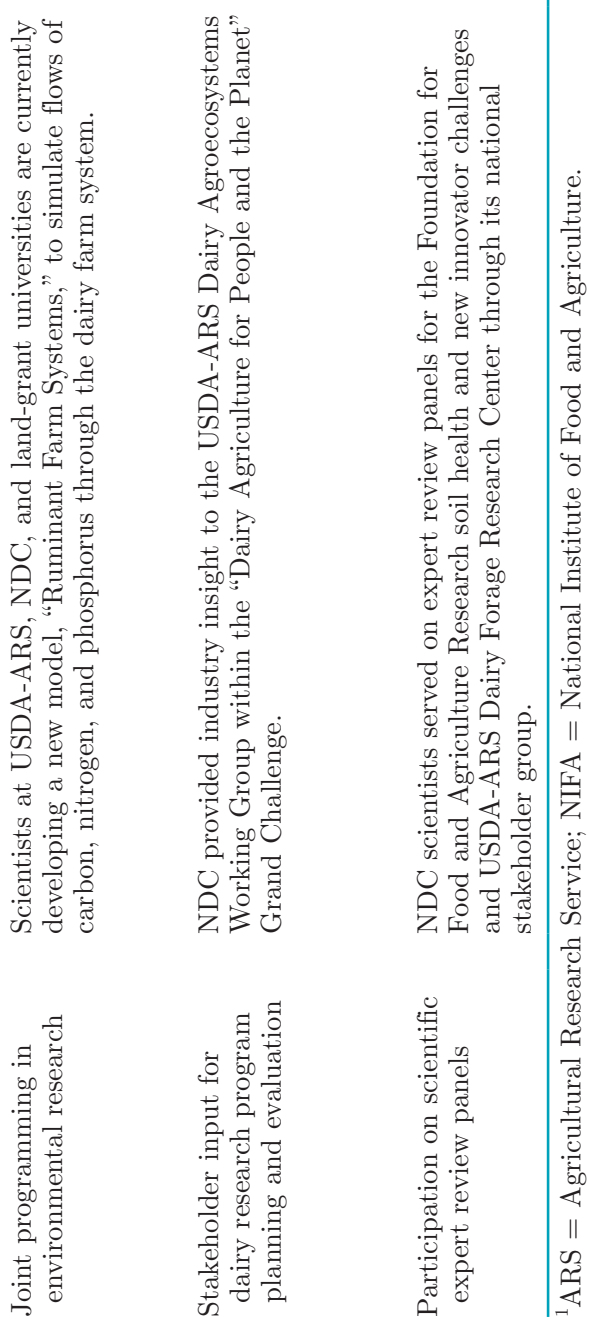


build the framework for research roadmap topics that could be addressed through partnership between USDA and NDC (Table 2). The following section provides details of the discussion between academic, federal, and industry partners.

\section{Human Nutrition}

Outcomes from the breakout session on human nutrition were presented with agreed-upon topics of collaboration in research and extension that included dairy food composition and the role of dairy in sustainable, nutritious diets and whole-milk dairy foods. Within these topic areas, the key research and extension questions to be addressed included the following:

- What is the composition of dairy products, beyond basic nutrients?

- How do USDA-recommended dietary patterns align with sustainable diets?

- How do whole-milk dairy foods fit into healthy dietary patterns, particularly in children and elderly populations?

To build the research and extension coordination roadmap necessary to address these topics, a working group will meet quarterly to achieve the following:

- Educate each other on existing projects and ones that could benefit from joint funding.

- Expand upon a previously approved USDA-NIFA workshop on bovine milk composition and how it affects human health to include joint funding to assess the impact on the USDA food database.

- Organize a meeting for the human nutrition working group in April 2019 to further develop and add details to the human nutrition portion of USDA-NIFA, ARS, and NDC research and extension coordination roadmap.

\section{Environmental Sustainability}

The outcomes of the breakout session on environmental sustainability were presented with topic areas for dairy research and extension that could be developed further through coordinated discussion and collaboration. The topic areas included consumer trust; dairy cow care and nutrition; the development of an integrated systems approach to measure and evaluate system-wide impacts and contributions from the dairy community; and innovations in tools and technologies. Within these topic areas, the key research and extension questions the breakout group discussed included the following:
- How can nutrition and environmental outputs (ecosystem services) be optimized?

- How can optimization of dairy systems occur on a landscape scale within the context of a global food system?

- How can the use of new technology to improve dairy farm labor, animal well-being, and milk quality be accelerated?

- How can consumer trust in agriculture and dairy foods be improved?

The breakout group agreed to reconvene by the end of 2018 to determine the research and extension steps necessary to address these topic areas.

\section{Food Safety}

The attendees of the food safety session discussed the importance of food safety, key risk areas to focus on, and an aspirational goal to never have anyone become sick from eating dairy. Education through outreach and extension was identified as a key need to improve dissemination and adoption of science-based information and best practices to the broader dairy community, including small-scale or artisan producers. The need to improve education on the risks associated with the consumption of raw milk was also discussed. Leveraging extension to share sanitation best practices for pathogen control across the dairy industry was identified as an important area of coordination and collaboration.

The group identified various challenges and gaps in current knowledge and arranged them into overarching topic areas. The topic areas for collaboration included new approaches to sanitation with an emphasis on both traditional and dry-powder environments and the development of a quantitative microbial risk assessment (QMRA) for dairy. Within these topic areas, the key research and extension questions that were discussed included the following:

- How can effective sanitation in production plants be improved?

- Where would a QMRA be focused and how would food-borne illness from dairy foods be prevented?

Next steps were also identified, including creation of an ongoing food-safety working group to further define research questions and areas of coordination and development of a dairy food safety coordination roadmap similar to the Dairy Agriculture for People and the Planet Grand Challenge (a USDA-ARS research effort). Further opportunities include inviting USDA scientists to join dairy community expert panels; finding opportunities for NDC and dairy community ex- 
TRICARICO ET AL.

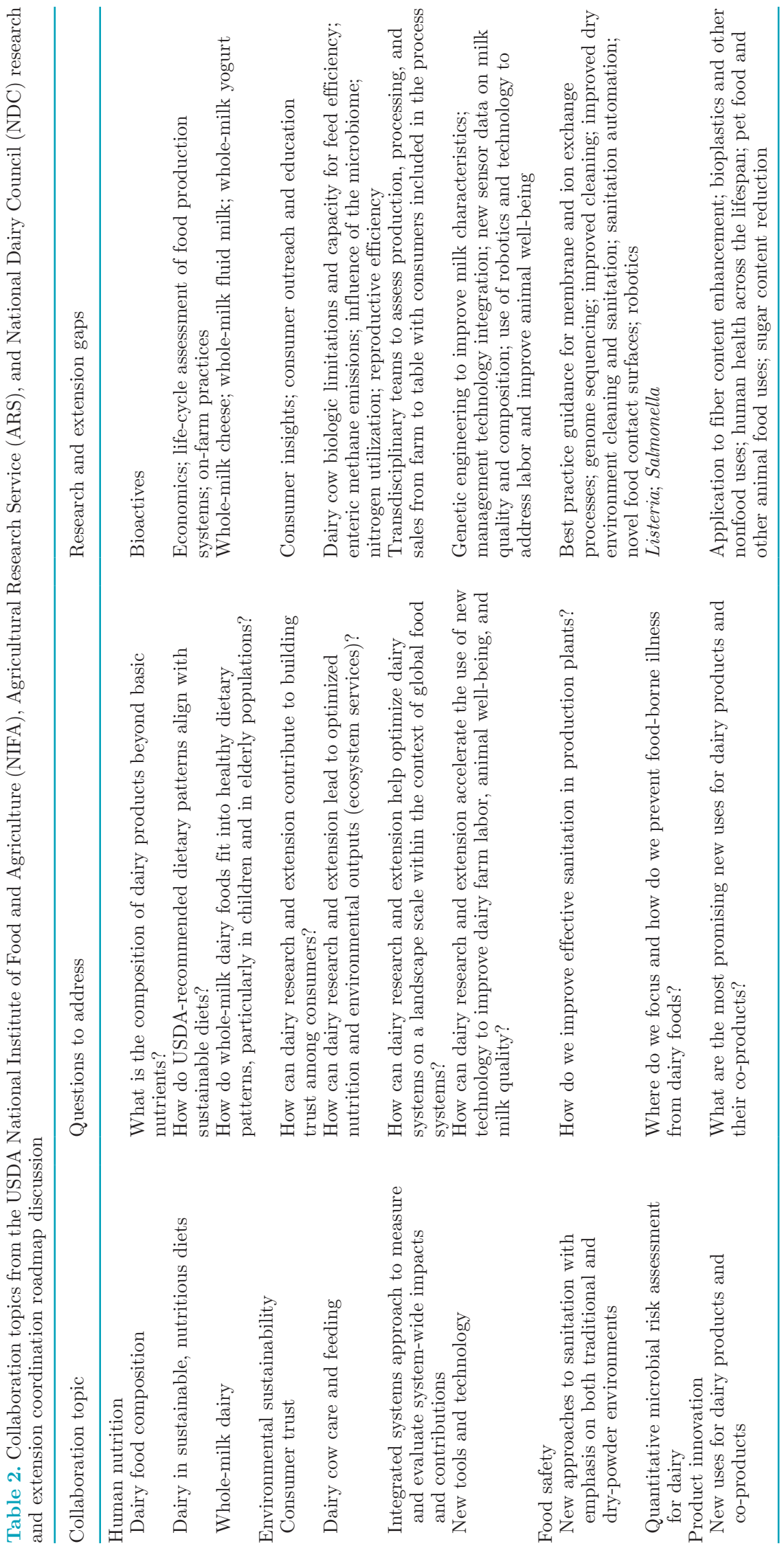


perts to attend USDA food safety-related meetings; a follow-up meeting with extension leadership to identify extension personnel activities and needs; developing an infographic for educational purposes; identifying review panel opportunities; and keeping the group informed of progress between now and the next meeting.

\section{Product Innovation}

The product innovation group presented agreed-upon areas of collaboration and coordination in research and extension. The product innovation breakout group stressed that research and extension are of growing importance to export markets and that there is a need to meet world market demands. The breakout group also agreed that sustainability and associated reductions in food and water waste, and education and extension for processors, the public, and other audiences are other important areas where public and private coordination are needed.

The group also recognized the opportunities and barriers in funding. They noted that although the American Dairy Products Institute is a potential partner for nonhuman food research, USDA-NIFA is a partner to work with in identifying grant opportunities, particularly programs in the Agriculture and Food Research Initiative. The group also noted that training researchers to improve their science communication skills is important.

Topic areas for collaboration include new uses for dairy products and co-products and technology enhancement. Within these topic areas, the key research and extension questions to be addressed included the following:

- What are the most promising new uses for dairy products and their co-products?

- What technologies will best enhance efficiency, sustainability, and innovation?

The product innovation group agreed that next steps include reconvening to write the research and extension coordination roadmap; having further discussions with NIFA on grant program opportunities and using the knowledge gained to coordinate identified research and extension programs with suitable grant opportunities; and having both university and dairy community representatives provide input on dairy product research and extension needs to NIFA Listens (https://nifa.usda .gov/nifalistens) and related stakeholder listening sessions of other funding organizations.

\section{CONCLUSIONS}

The "Elevating Dairy Research and Extension Through Partnership" meeting in 2018 provided a forum to expand the partnership between USDA-ARS, USDA-NIFA, NDC, academic scientists, and extension specialists. It also emphasized the importance of extension professionals working closely with research scientists to identify and comprehensively address critical needs. Meeting attendees identified key areas of strategic alignment and began discussing the development of a dairy research and extension coordination roadmap to ensure that nutritious, safe, and sustainable dairy foods are available to meet consumer needs. Although this conference represents the second of two joint USDA-NDC meetings, it also represents an important next step in identifying the partnerships and research questions vital to not only supporting dairy agriculture but also improving the health and well-being of consumers. Research and extension specialists in the areas of human nutrition, environmental sustainability, food safety, and product innovation will continue to discuss and develop a research and extension coordination roadmap that addresses these needs. The roadmap is expected to be completed by the end of 2019 and will be shared widely with academia and federal partners, the greater dairy community, and other stakeholders.

\section{ACKNOWLEDGMENTS}

The authors acknowledge the meeting participants, many of who made valuable contributions to the discussion. Chavonda Jacobs-Young, USDA, acting chief scientist, acting deputy undersecretary, Research, Education, and Economics, administrator, ARS, presented the keynote address. Other invited speakers included: Peggy Tomasula, PhD, research leader, USDA-ARS; John Lucey, PhD, director of the Center for Dairy Research at the University of Wisconsin-Madison; Steve Smith, PhD, national program leader, Animal Production Systems, USDA, NIFA; Mark Boggess, PhD, center director for USDA-ARS; Naomi Fukagawa, MD, PhD, director, USDA Human Nutrition Research Center, USDA-ARS; and Christopher Cifelli, PhD, vice president nutrition research, NDC. Nancy E. Sandbach, MS, $\mathrm{RD}, \mathrm{LDN}$, vice president, science \& research partnerships, NDC, and Thomas O'Connell, MBA, president, Marketing Concepts Inc., planned and executed the meeting. Beth Rice Bradley, PhD, owner, Foodsense LLC, contributed to drafting the manuscript. All authors read and approved the final manuscript. 


\section{REFERENCES}

Clancy, M., K. Fuglie, and P. Heisey. 2016. US agricultural R\&D in an era of falling public funding. Accessed Dec. 3, 2018. https://www .ers.usda.gov/amber-waves/2016/november/us-agricultural-rd-in -an-era-of-falling-public-funding/.

Drewnowski, A. 2018. Measures and metrics of sustainable diets with a focus on milk, yogurt, and dairy products. Nutr. Rev. 76:21-28.

Fulgoni, V. L. 3rd, D. R. Keast, N. Auestad, and E. E. Quann. 2011. Nutrients from dairy foods are difficult to replace in diets of Americans: Food pattern modeling and an analyses of the National Health and Nutrition Examination Survey 2003-2006. Nutr. Res. 31:759-765.

Gerber, P. J., and H. Steinfeld. 2008. Global environmental consequences of the livestock sector's growth. Outlook Agric. 37:7-13.

Henderson, A. D., A. C. Asselin-Balencon, M. Heller, L. Lessard, S. Vionnet, and O. Jolliet. 2017. Spatial variability and uncertainty of water use impacts from U.S. feed and milk production. Environ. Sci. Technol. 51:2382-2391.

Holly, M. A., P. J. Kleinman, R. B. Bryant, D. L. Bjorneberg, C. A. Rotz, J. M. Baker, M. V. Boggess, D. K. Brauer, R. Chintala, G. W. Feyereisen, J. D. Gamble, A. B. Leytem, K. F. Reed, P. A. Vadas, and H. M. Waldrip. 2018. Short communication: Identify- ing challenges and opportunities for improved nutrient management through the USDA's Dairy Agroecosystem Working Group. J. Dairy Sci. 101:6632-6641.

Perdue, S. 2017. Report to the President of the United States from the Task Force on Agriculture and Rural Prosperity. Accessed Aug. 23, 2018. https://www.usda.gov/sites/default/files/documents/ rural-prosperity-report.pdf.

Slimko, M. L., J. Tricarico, and G. D. Miller. 2017. Proceedings from the United States Department of Agriculture and National Dairy Council Collaborative Research Planning Meeting Held August 24, 2016. J. Food Sci. 82:1513-1515.

Thoma, G., J. Popp, D. Nutter, D. Shonnard, R. Ulrich, M. Matlock, D. Kim, Z. Neiderman, N. Kemper, C. East, and F. Adom. 2013. Greenhouse gas emissions from milk production and consumption in the United States: a cradle-to-grave life cycle assessment circa 2008. Int. Dairy J. 31(Suppl. 1):S3-S14.

USDA. 2017. USDA-NIFA Award. National Dairy Food Safety Plan Coaching Workshop. Accessed Aug. 23, 2018. https://portal.nifa .usda.gov/lmd4/recent_awards?report_title=RecentAwards\&from site $=$ NIFA\&search_label $=$ Awards Listing.

White, R. R., and M. B. Hall. 2017. Nutritional and greenhouse gas impacts of removing animals from US agriculture. Proc. Natl. Acad. Sci. USA 114:E10301-E10308. 